\title{
The Effects of the Health Insurance Card Scheme on Out-of-Pocket Expenditure Among Migrants in Ranong Province, Thailand
}

This article was published in the following Dove Press journal: Risk Management and Healthcare Policy

\author{
Rapeepong Suphanchaimat (D) ${ }^{1,2}$ \\ Watinee Kunpeuk (iD) \\ Mathudara Phaiyarom' \\ Sirinard Nipaporn ${ }^{3}$ \\ 'International Health Policy Program, \\ Ministry of Public Health, Nonthaburi \\ I 1000, Thailand; ${ }^{2}$ Division of \\ Epidemiology, Department of Disease \\ Control, Ministry of Public Health, \\ Nonthaburi II 000 , Thailand; ${ }^{3}$ National \\ Health Security Office, Bangkok 10210 , \\ Thailand
}

\begin{abstract}
Introduction: Although Thailand achieved Universal Health Coverage since 2002, there remained gaps in the insurance coverage as undocumented migrants were ineligible to be enrolled in the national public insurance. In 2004 the Thai Ministry of Public Health implemented the Health Insurance Card Scheme (HICS) to cover undocumented migrants. The objective of this study was to investigate the effect of the HICS on out-of-pocket payments (OOP) made by migrant patients at point of care.
\end{abstract}

Methods: The study applied quantitative methods, using individual patient records from one provincial hospital, one district hospital and two health centers between 2011 and 2015 . Ranong province was chosen as a study site as it had the largest proportion of migrants to Thai residents compared with other provinces. Descriptive and inferential statistics were employed. In descriptive statistics, mean and median were used. In inferential statistics, the two-part model (TPM) was applied to examine the relationship between the HICS and OOP for both outpatient (OP) and inpatient (IP) care.

Results: The HICS reduced IP and OP OOP expenditures by 2471 Baht (US\$ 75) and 293 Baht (US\$ 9) respectively. The attributes contributed to the reduction of IP and OP OOP included insurance status, residential address close to the facilities, and a history of visiting health facilities after 2013 (the year that the HICS expanded its benefit package). In contrast, severe illness, and advanced age were expected to increase IP and OP OOP.

Conclusion: The HICS appeared to reduce the financial burden from accessing care among its beneficiaries. Future studies to explore supply-side financing and equity aspects of the impact of HICS on OOP are recommended.

Keywords: migrants, out-of-pocket expenditure, two-part model, health insurance

\section{Introduction}

Recently, international migration has been growing speedily due to advanced transportation, economic pressures and political conflicts. The estimated number of international migrants in 2018 was about 244 million in 2018 (3.3\% of the global population), and this number is predicted to reach 405 million by $2050 .{ }^{1,2}$

It is widely known that many migrants face barriers to healthcare services. Global migration and health is therefore one of the major discourses in the global public health arena. ${ }^{3}$ The global effort to protect migrants' health can be observed in many high-level political dialogues, such as the United Nations General Assembly in 2006, the World Health Assembly (WHA) Resolutions (WHA60.26, WHA61.17 and WHA70.15), and the Global Compact for Safe, Orderly and
Correspondence: Rapeepong

Suphanchaimat

Tel +66-2-590-2366

Fax +66-2-590-2385

Email rapeepong@ihpp.thaigov.net 
Regular Migration recently adopted by the member states of the United Nations in 2018. ${ }^{3-6}$ In addition, since 2015, migrant health has been included in the Sustainable Development Goals (SDG) as part of the concept of Universal Health Coverage (UHC) that "no one" must be left behind. ${ }^{7}$ Despite this awareness and progress to take into account the health and social development of migrants, in reality, there always remain many challenges to translate this concept into concrete actions.

Southeast Asia is one of the most dynamic regions in the world in terms of economic development and population movement. ${ }^{8}$ Among the counties within the region, Thailand is a significant destination of migration, especially for those journeying from Cambodia, Lao PDR, and Myanmar (CLM). The accumulated number of CLM migrants living in Thailand each year is around three to four million and the majority of them crossed the border unlawfully - thus being recognized as undocumented migrants. $^{9}$

Theoretically, according to the Thai immigration laws, undocumented migrants must be deported. However, as these migrants are the key contributor of the Thai economy, most of the time, the Thai Government adopted lenient measures through the nationality verification (NV) policies which aimed to "legalize" the undocumented migrants so that they can live and work in the country lawfully for a certain period of time. ${ }^{10}$ Parallel to the NV is the instigation of health insurance for migrants, namely, the Health Insurance Card Scheme (HICS). The HICS provides comprehensive benefit package including outpatient care, inpatient care, emergency care and health promotion. The Ministry of Public Health (MOPH) is the main governing body of the HICS. To be enrolled in the HICS, a migrant applicant needed to pay for the premium at about 1300 Baht (US\$ 39) for 1 year of coverage plus 600 Baht (US\$ 18) for pre-enrolment health screening (the price in 2004).

In 2013 there were two remarkable changes in the HICS. First, its benefit package was expanded to cover some high-cost treatments such as chemotherapy and antiretroviral treatment (ART) for migrants suffering from HIV/AIDS. The widening of benefit came along with the rise in the premium. At that time, the HICS premium increased from 1300 Baht (US\$ 39) to 2200 Baht (US\$ 67). Second, the HICS allowed migrant child to be insured on a voluntary basis. The premium for a migrant child was 365 Baht (US\$ 11) with the benefit coverage similar to a migrant adult.
Note that the situation changed after the military coup in 2014 when there was a massive exodus of Cambodia migrants back home for fear that the strict repatriation measure would be enforced during the military regime. To this end, the MOPH decided to reduce the HICS premium to 1600 Baht (US\$ 48) and decreased the health check cost to 500 Baht (US\$ 15) in order to attract more migrants to be enrolled in the scheme. ${ }^{11,12}$

Though the issue of migrant health has been on political spotlight in Thailand for years, there are still gaps in knowledge. So far most research on migrants in Thailand has been focusing on the service component and risk behavior while research on financing aspect is quite sparse, particularly the financing study with regard to the HICS. ${ }^{13}$ This study thus aimed to investigate the effects of the HICS in relation to the financial burden, as measured by the degree of out-of-pocket payment (OOP), from enjoying services at public health facilities in both insured and uninsured migrants. It is hoped that the findings from this study can help extend the value and academic richness of public health research on migrant health in Thailand.

\section{Methods}

\section{Study Site}

Ranong province was selected as the study site since it has the highest proportion of registered migrants compared with other provinces in Thailand (Figure 1). Ranong is facing a significant burden of migration from neighboring countries. Due to its location and a shared border with Myanmar, Ranong has a significant population mix with a diversity of Thais, Burmese migrants and displaced Thais. Most of these migrants are working in the agricultural and fishery sectors.

\section{Data Sources}

The study employed facility-based data, which recorded the attendance of inpatients (IP) and outpatients (OP). All visits between 2011 and 2015 were collected. The data were obtained from Ranong Provincial Hospital in Mueang district, Kraburi District Hospital in Kraburi district and two health centers (one in each district). Mueang and Kraburi are the most migrant populated districts in Ranong. The OP data were analyzed from these four facilities. However, as the health centers normally do not have admission beds and there were problems in the electronic software used to retrieve the data in Ranong Provincial Hospital, thus for IP, only Kraburi District 


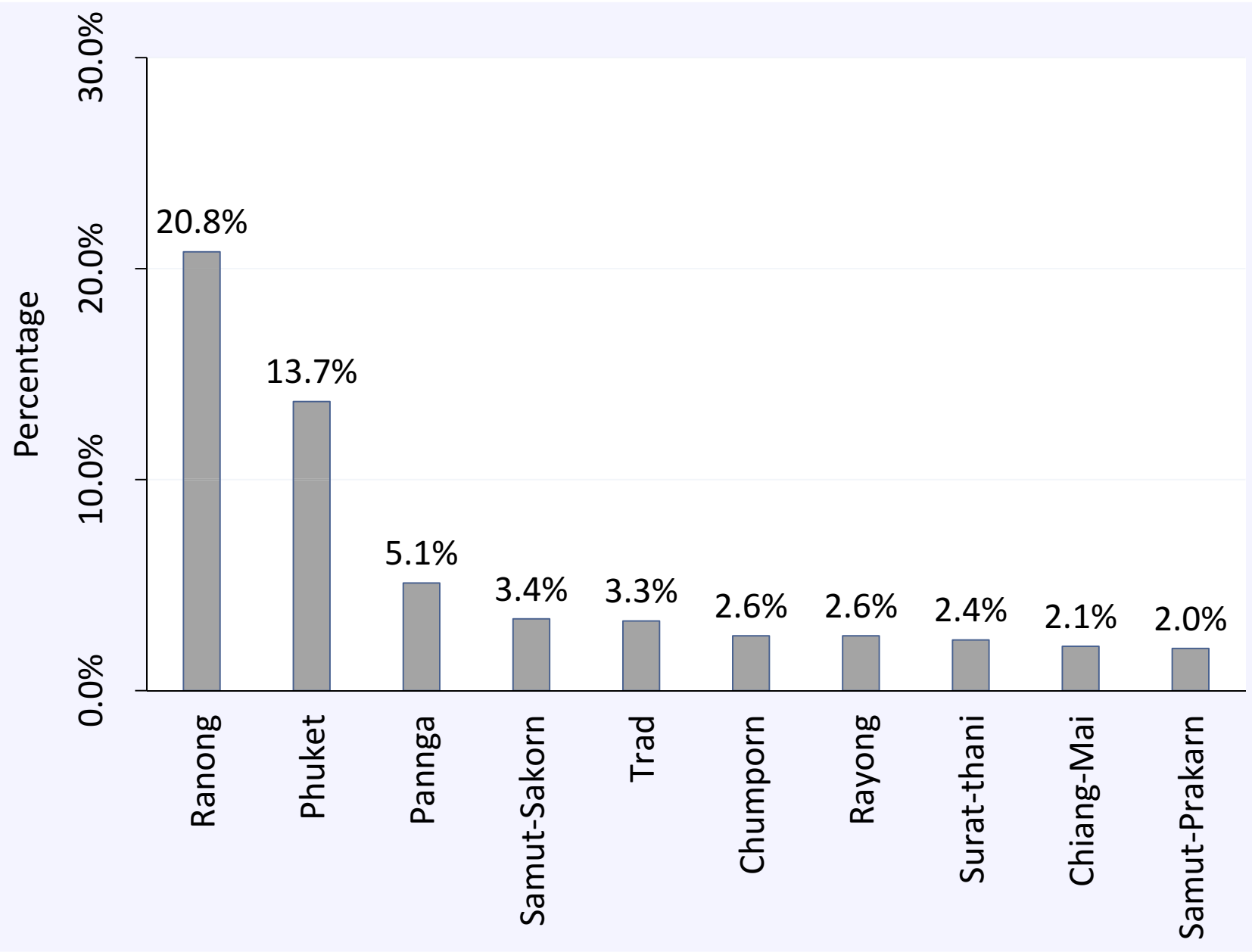

Figure I Top-ten provinces with the largest proportion (\%) of insured migrants to Thai citizens.

Notes: Data from Health Insurance Group, Office of the Permanent Secretary, the MOPH and National Statistical Office of Thailand. ${ }^{12,29}$

Hospital's dataset was available for the analysis. Also, incompleteness of OP data in year 2011 was observed. Due to these challenges, the analysis of OP data lasted from 2012 to 2015 . It should be noted that the study excluded admission records of normal newborn delivery as they could be a duplication of maternal admissions. The summary of data and health facilities is shown in Table 1 .

\section{Data Analysis}

The analysis consisted of two steps. First, descriptive statistics were used to capture the number of visits among the HICS insurees and uninsured migrants. Baseline characteristics between the HICS insurees and the uninsured were examined by Chi-square test. Analysis of Variance (ANOVA), Student's $t$-test, Kruskal-Wallis test, and Wilcoxon rank-sum test were used to assess the degree of OOP difference with reference to each covariate.

Second, the relationship between the HICS and OOP was explored by econometric techniques. Since the HICS has been evolved over time, it is less feasible to identify an exact time cut-off, which time point is "before" and which

Table I Overview of the Data in Each Health Facility Used for the Analysis

\begin{tabular}{|l|l|l|l|l|l|}
\hline \multirow{2}{*}{ Data } & \multicolumn{2}{|l|}{ Mueang } & Kraburi & \multirow{2}{*}{ Year } \\
\cline { 2 - 6 } & Ranong Hospital & Heath Center A & Kraburi Hospital & Health Center B \\
\hline Inpatient & Not available & Not available & $\checkmark$ & Not available & $2011-2015$ \\
Outpatient & $\checkmark$ & $\checkmark$ & $\checkmark$ & $\checkmark$ & $2012-2015$ \\
\hline
\end{tabular}


is "after". As a result, a "treatment-control" comparison is more feasible. In this case, the HICS insurees are considered treatment, while uninsured migrants were identified as control.

Due to the unique characteristics of health expenditure data which have excess zeros and heavy right tails, the two-path model (TPM) was employed instead of conventional regression. ${ }^{14}$ The TPM consisted of two stages. The first stage used logistic regression to estimate the likelihood of incurring OOP, while the second part used Generalized Linear Model (GLM) with gamma distribution to identify the amount paid once payment occurred. Finally, both stages were combined to estimate the final OOP. The advantage of TPM is that it enables the researchers to take into account (1) the probability of making a payment, and (2) the amount paid for records with a payment (at any Baht), simultaneously.

It is worth noting a couple of important points. First, the analysis excluded Thai patients. This is because, according to the Thai byelaws, all Thai citizens are covered by the Universal Coverage Scheme (UCS), the national insurance arrangement for all Thai nationals since birth. Second, OOP in this study meant the expenditure spent by patients and not the unit cost incurred by health facilities.

\section{Variable Management}

Insurance variable was the main outcome of interest. This variable was coded 0 for the uninsured, and 1 for the HICS insurees. The model also controlled for other covariates, including sex (male/female), age groups (0-7 years, 8-15 years, 16-30 years, 31-60 years, and over 60 years), disease diagnosis (using International Classification of Diseases version 10 [ICD10] and the Diagnostic Related Groups [DRG]), hospital level (provincial hospital/district hospital), and domicile of a patient.

There were few variables that needed special treatment before undertaking the analysis. First is the DRG variable. In the Thai healthcare system, the DRG is the main indicator for measuring severity of diseases in IP care and the facilities can be reimbursed for IP treatment expense based on the DRG. It captures information on patients' age and sex, presence of co-morbidities and complications, and procedures performed. A five-digit code is constructed for each admission, where the fifth code indicates illness severity (ranging from 1 to 5 scales). ${ }^{15-17}$ Any admission with the fifth code of DRG equaling two or above was labeled as severe condition.
Second, the domicile variable was labeled as proximity to facility and non-proximity to facility. If any individual had residential address situated in the same district where the facility was situated it would be coded 1; and 0 if otherwise.

Third, another binary variable, namely, time, was included in the analysis. It was constructed as binomial variable, coded as pre-2013 and post-2013. The reason for using year 2013 as a cut-point was that year 2013 was the time when the HICS expanded its benefit to cover high-cost treatment including HIV/AIDS. This meant, theoretically, after-2013 OOP was likely to be lower than post-2013 OOP.

Fourth, for routine OP care, the DRG system had not been installed in most MOPH-affiliated facilities. As a result, ICD-10 was used instead of DRG. A new categorical variable called principal diagnosis was constructed. The variable was coded 1 for non-specific diagnosis, 2 for Z-group diagnosis, and 3 for Ambulatory Care Sensitive Condition (ACSC) diagnosis. The Z-group referred to any diagnosis where ICD-10 started with $Z$. This covered a number of minor illnesses and disease prevention activities such as wound dressing, medical counseling, vaccination and family planning. The ACSC was used as a proxy for severe diseases. More details of the ACSC are presented in Table S1. ${ }^{18,19}$ Other diagnoses that did not fall in the ACSC and Z-group categories were considered as nonspecific OP diagnosis.

Lastly, a new variable that reflected level of care was added (coded as 1 for health centre, 2 for district hospital, and 3 for provincial hospital).

All calculations were conducted by STATA software version 14 (serial number $=401406358220)$.

\section{Results}

\section{Inpatient Care}

A total of 3845 visits were analyzed (uninsured $=1733$ and HICS = 2122). Baseline characteristics of the participants are demonstrated in Table 2. It appeared that the severity of diseases did not show much difference between the HICS patients and the insured, despite somewhat differences in other profiles. The majority of the HICS insurees were of the middle age groups. By contrast, nearly one third of the insurees were children aged not more than 7 years. The sex and domicile profiles saw marginal difference between the beneficiary types despite the statistical significance shown. The share of admissions after 2013 amounted to about $40 \%$ of all admissions combined with a slightly higher share observed among the HICS insurees. 
Table 2 Baseline Characteristics of the HICS Insurees and the Uninsured for IP Admissions

\begin{tabular}{|c|c|c|c|}
\hline Variable-n (\%) & Uninsured $(N=\mid 733)$ & HICS (N= 2I22) & P for Chi-Square Test \\
\hline $\begin{array}{l}\text { Sex } \\
\text { - Male } \\
\text { - Female }\end{array}$ & $\begin{array}{l}648(37.4) \\
1085(62.6)\end{array}$ & $\begin{array}{l}512(24.1) \\
1610(75.9)\end{array}$ & $<0.001$ \\
\hline $\begin{array}{l}\text { Illness } \\
\text { - Non-severe } \\
\text { - Severe }\end{array}$ & $\begin{array}{l}\text { I597 (92.2) } \\
\text { I36 (7.8) }\end{array}$ & $\begin{array}{l}1960(92.5) \\
159(7.5)\end{array}$ & 0.689 \\
\hline $\begin{array}{l}\text { Domicile } \\
\text { - Non-proximity } \\
\text { - Proximity }\end{array}$ & $\begin{array}{l}69(4.9) \\
1349(95.1)\end{array}$ & $\begin{array}{l}36(3.0) \\
1158(97.0)\end{array}$ & 0.016 \\
\hline $\begin{array}{l}\text { Time } \\
\text { - Pre-20I3 } \\
\text { - Post-20I3 }\end{array}$ & $\begin{array}{l}1123(64.8) \\
610(35.2)\end{array}$ & $\begin{array}{l}12 \mid 4(57.2) \\
908(42.8)\end{array}$ & $<0.001$ \\
\hline $\begin{aligned} & \text { Age group in years } \\
& \text { - } 0-7 \\
&- 8-15 \\
&- 16-30 \\
&- 31-60 \\
&->60\end{aligned}$ & $\begin{array}{l}557(32.2) \\
97(5.6) \\
638(36.8) \\
397(22.9) \\
43(2.5)\end{array}$ & $\begin{array}{l}70(3.3) \\
7(0.3) \\
1259(59.3) \\
766(36.1) \\
20(1.0)\end{array}$ & $<0.001$ \\
\hline
\end{tabular}

Note: Missing data not shown.

The overall information of the IP OOP (per admission) is presented in Table 3. The largest mean OOP was observed in the uninsured, at around 2461 Baht (US\$ 75). The median OOP of insured migrants was 30 Baht (US\$ 1). The large gap between mean OOP and median OOP implied that the data were heavily skewed. A slight decrease in mean OOP was reported in uninsured migrants while mean OOP of the HICS beneficiaries remained stable and small over the study period (Figure 2).

Results from the Student's $t$-test are shown in Table 4. On average, an insured migrant experienced IP OOP at approximately 34 Baht (US\$ 1), far smaller than IP OOP among uninsured migrants (2461 Baht or US\$ 75). The difference of IP OOP between uninsured and insured migrants exhibited a strong statistical significance $(\mathrm{P}<0.001)$. Males paid slightly more than females. Migrant patients with severe illness encountered higher expenditure than those with non-severe

Table 3 Summary of Descriptive Statistics of IP OOP per Admission (in Baht) by Insurance Schemes

\begin{tabular}{|l|l|l|l|l|}
\hline Beneficiary & $\begin{array}{l}\text { N- } \\
\text { visits }\end{array}$ & $\begin{array}{l}\text { Mean } \\
\text { (Standard } \\
\text { Deviation) }\end{array}$ & $\begin{array}{l}\text { Median } \\
\text { (Interquartile } \\
\text { Range) }\end{array}$ & $\begin{array}{l}\text { Min- } \\
\text { Max }\end{array}$ \\
\hline $\begin{array}{l}\text { Uninsured } \\
\text { HICS }\end{array}$ & 1733 & $\begin{array}{l}2460.5(1556.3) \\
342(101.8)\end{array}$ & $\begin{array}{l}2388(1968) \\
30(0)\end{array}$ & $\begin{array}{l}0-17,100 \\
0-3230\end{array}$ \\
\hline
\end{tabular}

illness, and patients living near the facility spent less than those living distant from the facility. After 2013, IP OOP dropped from 1236 (US\$ 37) to 955 Baht (US\$29).

The first part of the TPM showed that insured patients with HICS significantly reduced the likelihood and amount of IP payment at the facility. These estimates were supported by a negative coefficient in both parts as shown in Table 5. The -7.6 coefficient implied that the odds of having IP OOP among insured migrants were about 0.005 times (an exponential of -7.6) compared to uninsured migrants. The -3.0 coefficient in the second part denoted that, once payment occurred, the HICS insurees paid about 5\% (an exponent of -3) as large as the payment paid by uninsured migrants. When both parts combined, the HICS significantly decreased IP OOP by around 2471 Baht (US\$ 75) per IP visit $(\mathrm{P}<0.001)$. In addition, OOP tended to decline by approximately 136 Baht (US\$ 4) after the year 2013. A history of severe illness potentially contributed to the increment of IP OOP by 426 Baht (US\$ 14). The working-age group (16-30 years) tended to pay more for IP care than the other age groups.

\section{Outpatient Care}

A total of 156,343 visits were found in OP care (uninsured $=59,648$ and HICS $=96,695$ ). The demographic profiles of the OP patients are displayed in Table 6. Most 


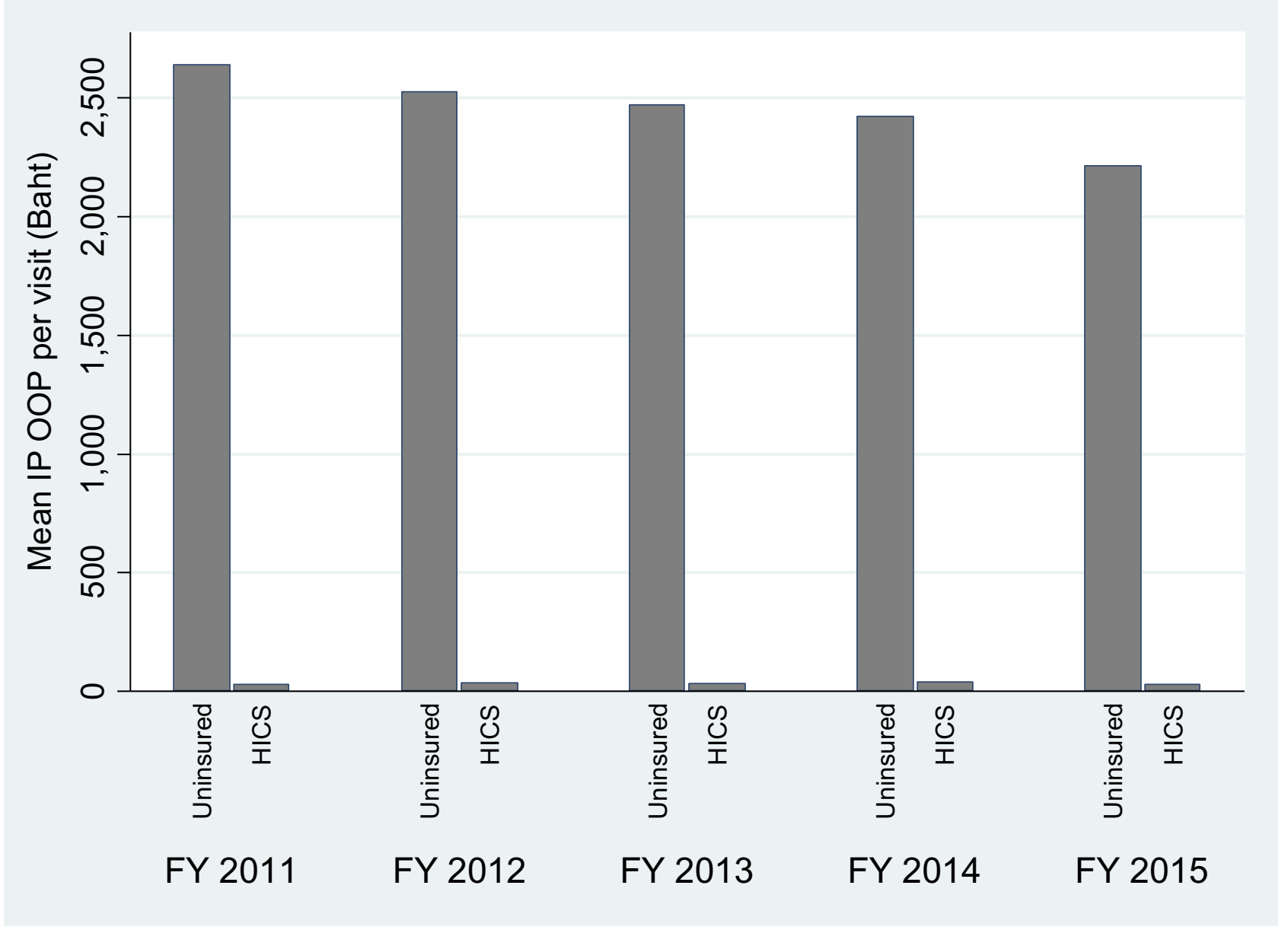

Figure 2 Mean IP OOP per admission by insurance schemes across years.

uninsured migrants utilised OP care due to Z-group conditions. Non-specific diagnoses were the most common reason for OP use among the HICS insurees. The proportion of OP visits at health centre and district hospital of the uninsured was greater than that of the HICS counterparts. More than $90 \%$ of the HICS patients had residential address proximate to the health facilities while only twothird of the uninsured did. The lion share of OP care in the uninsured happened before 2013. Approximately a quarter of OP visits among the uninsured were due to children aged 0-7 years, about fivefold greater (in terms of percentage) than OP visits in the HICS beneficiaries at the same age.

The analysis on OP OOP was performed in a similar fashion to IP OOP. On average, uninsured patients had OP OOP by approximately 420 Baht (US\$ 13). The OOP of the HICS patients showed a median of 22 Baht (US\$ 0.7). Over the four-year period, from 2012 to 2015, the mean OP OOP exhibited a downward trend among uninsured patients but there was no obvious change in the trend of OP OOP in the HICS insurees (Table 7 and Figure 3).

The univariable analysis suggested that higher OP OOP was found among the uninsured than insured migrants. The gap between OP OOP between the uninsured and insured migrants was about 398 Baht (US\$ 12). After 2013, the OP OOP diminished by almost half. Other covariates including Z-group diagnosis, visiting district hospital and non-proximity to a health facility, were likely to be correlated with increasing OOP (Table 8).

The TPM suggested that (after combining both analysis parts) the HICS appeared to be the strongest determinant that significantly contributed to the reduction of OOP by about 293 Baht (US\$ 9) (P < 0.001). Other covariates, such as proximity to healthcare providers, post-2013 time point, and Z-group diagnosis, also showed a significant impact in scaling down OP OOP (Table 9). 
Table 4 Comparing IP OOP (in Baht) by Personal Attributes and Insurance Schemes

\begin{tabular}{|c|c|c|c|c|}
\hline Variable & Mean & $\begin{array}{l}\text { Standard } \\
\text { Deviation }\end{array}$ & $\begin{array}{l}\text { P for Student's } t \text {-Test or } \\
\text { ANOVA }\end{array}$ & $\begin{array}{l}\text { P for Wilcoxon Rank-Sum Test or Kruskal- } \\
\text { Wallis Test }\end{array}$ \\
\hline $\begin{array}{l}\text { Insurance } \\
\text { - Uninsured } \\
\text { - HICS }\end{array}$ & $\begin{array}{l}2460.5 \\
34.2\end{array}$ & $\begin{array}{l}1556.3 \\
101.8\end{array}$ & $<0.001$ & $<0.001$ \\
\hline $\begin{array}{l}\text { Sex } \\
\text { - Male } \\
\text { - Female }\end{array}$ & $\begin{array}{l}1299.7 \\
1049.8\end{array}$ & $\begin{array}{l}1770.4 \\
1510.9\end{array}$ & $<0.001$ & $<0.001$ \\
\hline $\begin{array}{l}\text { Illness } \\
\text { - Non-severe } \\
\text { - Severe }\end{array}$ & $\begin{array}{l}1101.8 \\
1415.2\end{array}$ & $\begin{array}{l}1545.2 \\
2112.6\end{array}$ & 0.001 & 0.133 \\
\hline $\begin{array}{l}\text { Domicile } \\
\text { - Non-proximity } \\
\text { - Proximity }\end{array}$ & $\begin{array}{l}1689.2 \\
1316.6\end{array}$ & $\begin{array}{l}1742.1 \\
1638.4\end{array}$ & 0.023 & 0.013 \\
\hline $\begin{array}{l}\text { Time } \\
\text { - Pre-2013 } \\
\text { - Post-2013 }\end{array}$ & $\begin{array}{l}1235.5 \\
954.8\end{array}$ & $\begin{array}{l}1642.7 \\
1509.6\end{array}$ & $<0.001$ & $<0.001$ \\
\hline 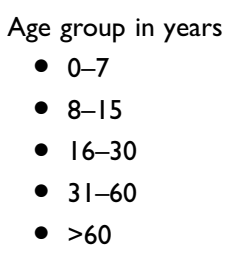 & $\begin{array}{l}1803.5 \\
2194.5 \\
963.2 \\
905.2 \\
1547\end{array}$ & $\begin{array}{l}1559.6 \\
1325.4 \\
1522.6 \\
1592.7 \\
2053.8\end{array}$ & $<0.001$ & $<0.001$ \\
\hline
\end{tabular}

\section{Discussion}

\section{Result Discussion}

Thailand is one of the few countries where undocumented and documented migrants can receive health coverage regardless of their resident status and were eligible to the public insurance, namely, the HICS. ${ }^{20}$ This study is probably the first paper that systemically examined the impact of the HICS on OOP among migrant patients in Thailand. The findings suggest that the HICS helped decrease both IP OOP and OP OOP significantly.

There exists some prior research on the public health field outside Thailand that shows the financial benefit of health insurance among the insurees. Previous research in China reported that a number of state-run insurance schemes (for example, the New Rural Cooperative Medical Scheme and Urban Employee-based Basic Medical Insurance) could lower the percentage share of OOP among rural-to-urban internal migrants by about $34 \%{ }^{21}$ Another study in China also highlighted the benefit of health insurance to minimize the likelihood of OOP paid by migrants of working age and elderly migrants. ${ }^{22}$
Similarly, a study by Kominski et al reviewed the impact of the Affordable Care Act (ACA), which aimed to enhance the coverage of health insurance to low- and middle-income individuals in the US. Their findings showed that the introduction of ACA led to a significant decline of OOP among its insurees. ${ }^{23}$

In details, the results above showed that the period after 2013 led to a significant reduction in both IP OOP and OP OOP. This might be explained by the expansion of HICS beneficiaries to cover HIV/AIDS and high-cost treatments. Apart from this, the geographical effects as measured by residence location also influence the payment at point of care. This is because a patient whose residential address is not in the responsible area of the hospital might likely bypass the primary-registered hospital and visited the nearby hospital instead. This situation could incur some treatment expenses (unless a referral sheet was issued from the primary-registered hospital).

Over the study period, there was a downward trend in the mean of OP OOP among uninsured patients, as presented in Figure 3. This phenomenon was possibly caused 
Table 5 Multivariable Regression of IP OOP (in Baht) by the TPM

\begin{tabular}{|c|c|c|c|c|c|c|}
\hline \multicolumn{2}{|l|}{ Variable } & $\frac{\text { Coef }}{-7.649}$ & $\begin{array}{l}\text { SE } \\
0.399\end{array}$ & $\frac{\mathbf{P}}{<0.001}$ & \multicolumn{2}{|c|}{ 95\% Confidence Interval } \\
\hline Part I & $\begin{array}{l}\text { Insurance ( } v \text { uninsured) } \\
\text { Severe illness ( } v \text { not having) } \\
\text { Insurance\#\# Severe illness } \\
\text { Post-20I3 ( } v \text { pre-20I3) } \\
\text { Insurance\#Post-20I3 } \\
\text { Female ( } v \text { male) } \\
\text { Age group ( } v \leq 7 \text { yr) } \\
\text { - } 8-15 \\
\text { - } 16-30 \\
\text { - } 31-60 \\
\text { - }>60 \\
\text { Proximity ( } \\
\text { Constant non-proximity) }\end{array}$ & $\begin{array}{l}-7.649 \\
-1.076 \\
1.496 \\
-0.792 \\
0.539 \\
0.782 \\
-0.539 \\
-0.850 \\
-1.105 \\
-2.612 \\
-0.672 \\
4.736\end{array}$ & $\begin{array}{l}0.399 \\
0.378 \\
0.835 \\
0.292 \\
0.505 \\
0.344 \\
\\
0.643 \\
0.368 \\
0.427 \\
0.542 \\
0.557 \\
0.640\end{array}$ & $\begin{array}{l}<0.001 \\
0.004 \\
0.073 \\
0.007 \\
0.286 \\
0.023 \\
\\
0.402 \\
0.021 \\
0.010 \\
<0.001 \\
0.228 \\
<0.001\end{array}$ & $\begin{array}{l}-8.431 \\
-1.817 \\
-0.140 \\
-1.364 \\
-0.451 \\
0.109 \\
-1.798 \\
-1.572 \\
-1.941 \\
-3.675 \\
-1.765 \\
3.481\end{array}$ & $\begin{array}{l}-6.866 \\
-0.334 \\
3.133 \\
-0.221 \\
1.530 \\
1.456 \\
\\
0.721 \\
-0.128 \\
-0.268 \\
-1.549 \\
0.420 \\
5.990\end{array}$ \\
\hline Part 2 & $\begin{array}{l}\text { Insurance ( } v \text { uninsured) } \\
\text { Severe illness ( } v \text { not having) } \\
\text { Insurance\# Severe illness } \\
\text { Post-20I3 ( } v \text { pre-20I3) } \\
\text { Insurance\#Post-20I3 } \\
\text { Female ( } v \text { male) } \\
\text { Age group ( } v \leq 7 \text { yr) } \\
\text { - } 8-15 \\
\text { - } 16-30 \\
\text { - } 31-60 \\
\text { - }>60 \\
\text { Proximity ( } v \text { non-proximity) } \\
\text { Constant }\end{array}$ & $\begin{array}{l}-3.047 \\
0.345 \\
-1.241 \\
-0.075 \\
0.880 \\
0.016 \\
0.121 \\
0.336 \\
0.223 \\
0.275 \\
-0.016 \\
7.632\end{array}$ & $\begin{array}{l}0.545 \\
0.070 \\
0.548 \\
0.036 \\
0.932 \\
0.043 \\
\\
0.062 \\
0.044 \\
0.054 \\
0.189 \\
0.082 \\
0.092\end{array}$ & $\begin{array}{l}<0.001 \\
<0.001 \\
0.024 \\
0.039 \\
0.345 \\
0.711 \\
\\
0.050 \\
<0.001 \\
<0.001 \\
0.145 \\
0.845 \\
<0.001\end{array}$ & $\begin{array}{l}-4.115 \\
0.209 \\
-2.315 \\
-0.146 \\
-0.947 \\
-0.069 \\
\\
0.000 \\
0.249 \\
0.117 \\
-0.095 \\
-0.177 \\
7.452\end{array}$ & $\begin{array}{l}-1.980 \\
0.482 \\
-0.167 \\
-0.004 \\
2.707 \\
0.101 \\
\\
0.242 \\
0.422 \\
0.329 \\
0.644 \\
0.145 \\
7.813\end{array}$ \\
\hline Both parts & 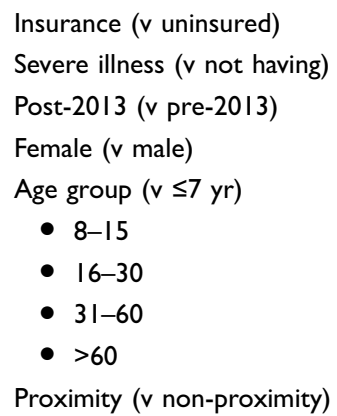 & $\begin{array}{l}-2470.710 \\
425.963 \\
-136.234 \\
60.860 \\
\\
124.222 \\
400.856 \\
224.493 \\
94.868 \\
-55.321\end{array}$ & $\begin{array}{l}45.185 \\
126.616 \\
48.277 \\
58.909 \\
77.126 \\
57.477 \\
70.437 \\
244.645 \\
110.728\end{array}$ & $\begin{array}{l}<0.001 \\
0.001 \\
0.005 \\
0.302 \\
0.107 \\
<0.001 \\
0.001 \\
0.698 \\
0.617\end{array}$ & $\begin{array}{l}-2559.27 \mid \\
I 77.800 \\
-230.855 \\
-54.600 \\
-26.94 \mid \\
288.203 \\
86.439 \\
-384.628 \\
-272.344\end{array}$ & $\begin{array}{l}-2382.150 \\
674.126 \\
-41.613 \\
176.320 \\
275.385 \\
513.508 \\
362.546 \\
574.364 \\
161.702\end{array}$ \\
\hline
\end{tabular}

Abbreviations: Coef, coefficient; SE, standard error.

by the introduction of an internal policy in Ranong province in 2011 which applied free-of-charge campaign for certain service items (for example, family planning, vaccination, and many Z-group diagnoses) for uninsured migrants. Ranong Provincial Public Health Office agreed to subsidize the cost of treatment for such service items for all public facilities in Ranong. ${ }^{13}$ The in-house policy within the province helped explain why hospital visits with Z-group diagnosis tended to make fewer OOP than those with other diagnoses (as demonstrated in Table 9). Furthermore, patients in Kraburi District Hospital tended to suffer more OOP than other health facilities. It could be postulated that citizens in Kraburi district were more likely to have better economic status than those in Mueang district. This is because most migrants in Mueang district lived in slum areas while those in Kraburi district mostly lived with Thai employees who possessed some land for rubber planting. Hence, migrants in Kraburi district might have higher ability to pay compared to migrants in Mueang district. However, this explanation is still a postulation which demands for further systematic investigation. 
Table 6 Baseline Characteristics of the HICS Insurees and the Uninsured for OP Visits

\begin{tabular}{|c|c|c|c|}
\hline Variable-n (\%) & Uninsured $(N=59,648)$ & HICS $(\mathrm{N}=96,695)$ & P for Chi-Square Test \\
\hline $\begin{array}{l}\text { Sex } \\
\text { - Male } \\
\text { - Female }\end{array}$ & $\begin{array}{l}28,949(48.5) \\
30,695(51.5)\end{array}$ & $\begin{array}{l}40,033(4 I .4) \\
56,662(58.6)\end{array}$ & $<0.001$ \\
\hline $\begin{array}{l}\text { Illness } \\
\begin{array}{l}\text { - Non-specific } \\
\text { - Z-group } \\
\text { - ACSC }\end{array}\end{array}$ & $\begin{array}{l}26,209(44.0) \\
27,163(45.5) \\
6276(10.5)\end{array}$ & $\begin{array}{l}50,663(52.4) \\
26,190(27.1) \\
19,842(20.5)\end{array}$ & $<0.001$ \\
\hline $\begin{array}{l}\text { Facility level } \\
\text { - Health centres } \\
\text { - District hospital } \\
\text { - Provincial hospital }\end{array}$ & $\begin{array}{l}4939(8.3) \\
17,163(28.8) \\
37,546(62.9)\end{array}$ & $\begin{array}{l}7311(7.6) \\
9756(10.1) \\
79,628(82.3)\end{array}$ & $<0.001$ \\
\hline $\begin{array}{l}\text { Domicile } \\
\text { - Non-proximity } \\
\text { - Proximity }\end{array}$ & $\begin{array}{l}17,663(32.8) \\
36,224(67.2)\end{array}$ & $\begin{array}{l}8580(9.6) \\
81,168(90.4)\end{array}$ & $<0.001$ \\
\hline $\begin{array}{l}\text { Time } \\
\text { - Pre-2013 } \\
\text { - Post-2013 }\end{array}$ & $\begin{array}{l}38,481(64.5) \\
21,167(35.5)\end{array}$ & $\begin{array}{l}52,724(54.5) \\
43,97 \mid(45.5)\end{array}$ & $<0.001$ \\
\hline 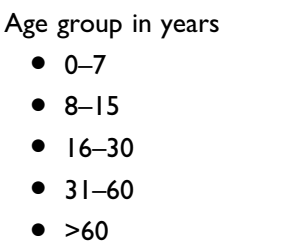 & $\begin{array}{l}14,632(24.5) \\
4228(7.1) \\
19,453(32.6) \\
18,224(30.6) \\
311 \mid(5.2)\end{array}$ & $\begin{array}{l}4731(4.9) \\
2043(2.1) \\
30,274(31.3) \\
49,916(51.6) \\
9730(10.1)\end{array}$ & $<0.001$ \\
\hline
\end{tabular}

Note: Missing data not shown.

Table 7 Summary of Descriptive Statistics of OP OOP per Visit (in Baht) by Insurance Schemes

\begin{tabular}{|l|l|l|l|l|}
\hline Beneficiary & $\begin{array}{l}\text { N- } \\
\text { Visits }\end{array}$ & $\begin{array}{l}\text { Mean } \\
\text { (Standard } \\
\text { Deviation) }\end{array}$ & $\begin{array}{l}\text { Median } \\
\text { (Interquartile } \\
\text { Range) }\end{array}$ & $\begin{array}{l}\text { Min- } \\
\text { Max }\end{array}$ \\
\hline $\begin{array}{l}\text { Uninsured } \\
\text { HICS }\end{array}$ & 59,648 & $\begin{array}{l}420.2(805.9) \\
22.2(147.4)\end{array}$ & $\begin{array}{l}100(383) \\
30(0)\end{array}$ & $\begin{array}{l}0-24,130 \\
0-16,000\end{array}$ \\
\hline
\end{tabular}

Severe illness and advanced age were determinants of increased IP OOP. It is not surprising that patients with severe illness were more likely to encounter higher treatment cost compared with patients with non-severe illness. With regard to age groups, the analysis showed that the higher the age was the greater the OOP incurred.

Though an investigation on health-seeking behavior of migrants was not the study's main objective from the first instance, this issue was partly explored through the comparison of patients' profiles in Tables 2 and 6. Disease patterns found in insured and uninsured migrants saw little difference for IP care, but not for OP care. This finding was similar to what Srithamrongsawat et al explained in the prior study. That is, the volume of IP care in uninsured migrants was on par with insured migrants; and uninsured migrants tended to utilize services only when their illness became more critical, which usually ended up with hospital admission. ${ }^{24}$ Another study by Pudpong et al also pointed to the same direction. ${ }^{25}$ For OP care, Z-group diagnosis gained the lion share of all OP visits made by uninsured migrants; unlike the HICS beneficiaries where the majority of visits did not fall into any particular diseases. A likely explanation for this phenomenon is the internal free-care policy for disease prevention services (mostly Z-group diagnosis) for uninsured migrants. This might entail a disproportionately greater share of Z-group diagnosis relative to other diseases. In addition, the volume of patients under 15 years was disproportionately high among the uninsured where the majority of insured migrants were of the working age. This might be because the legalization process of the Government resulted in the issuance of work permit and most hospitals used work permit as a pre-condition for the insurance enrollment. 


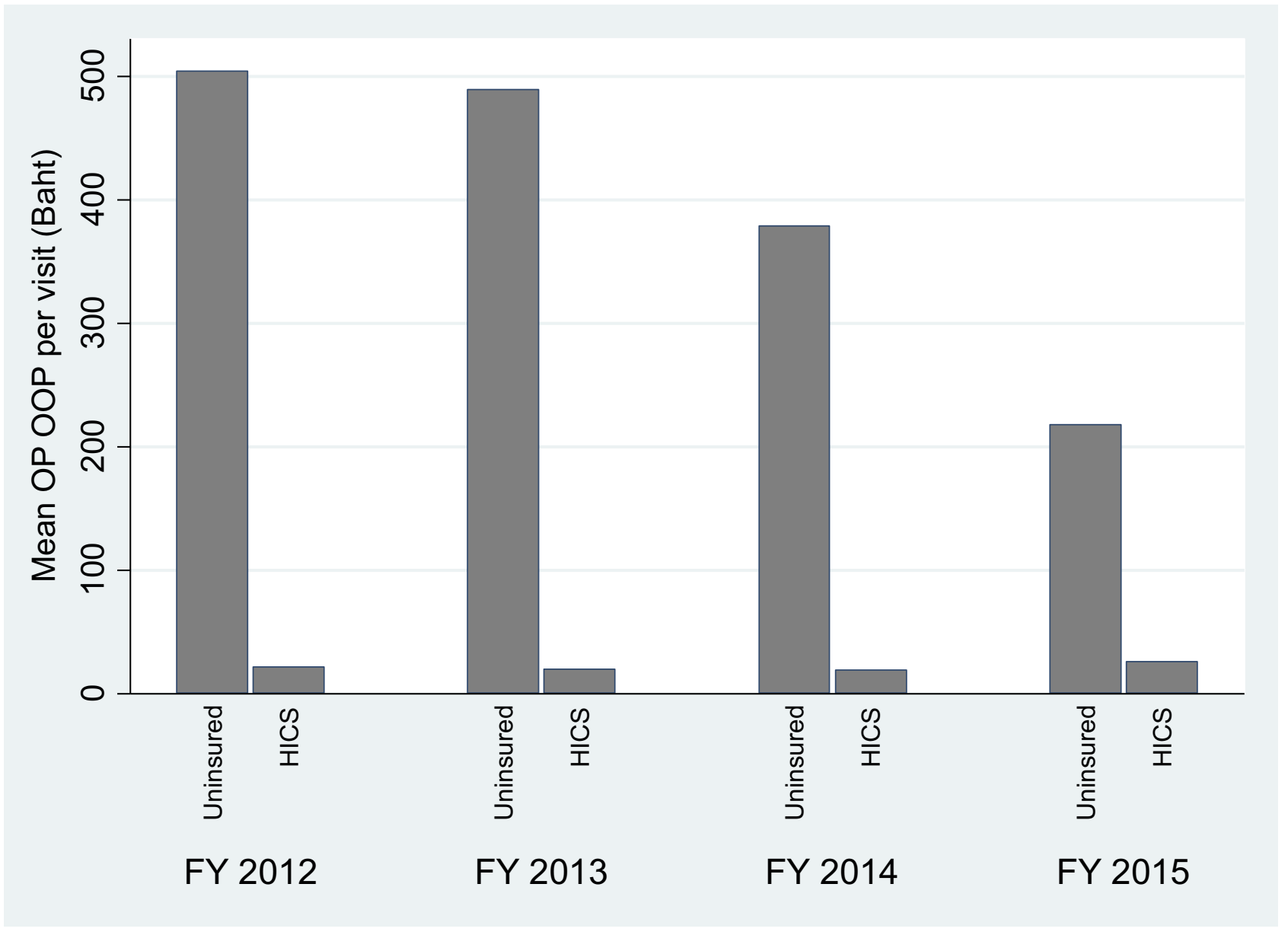

Figure 3 Mean OP OOP per visit by insurance schemes across years.

As, according to the Thai labor laws, a migrant child cannot enter the labor market and thus cannot obtain a work permit, some undocumented migrant children likely dropped out from the legalization process and were left without health insurance (unless their parents purchased the insurance for them on a voluntary basis). All of these differences of the patients' profiles warranted the use of multivariable analysis (like the TPM used in this study) to account for any potential confounding that might threaten the analysis validity.

\section{Methodological Discussion}

One of the key strengths of this study is that facility-based individual data were used in the analysis. The reliance on individual patient records from local providers enabled the researchers to gain rich information on services used on the ground. The authors did not depend on the MOPH data because in reality there is no requirement for local health offices to return their service data to the MOPH for healthcare cost reimbursement (as the HICS premium was paid directly to the local facilities). Hence, it would be more difficult to expect data completeness from the MOPH database relative to the local providers' dataset. Although there existed some previous studies that explored the financing issue in relation to migrant health in Thailand (such as Srithamrongsawat et al and Hasuwannakit), those studies heavily relied on aggregate data rather than individual data. This study thus helped extend the boundary of existing knowledge on migrant health in Thailand. ${ }^{24,26}$

Nevertheless, some limitations need to be acknowledged here. First, the generalizability of findings may be problematic as the unit of analysis in this study was not households. This meant that generalizability could be only applied to migrants presenting at a health facility, not all migrants across the country. The audiences should be reminded that it is very likely that this study missed data of persons who had never attended health facilities. In other words, selection bias might still persist; and to address this bias, further studies that extended from the facility level to the household level are needed. 
Table 8 Comparing OP OOP (in Baht) by Personal Attributes and Insurance Schemes

\begin{tabular}{|c|c|c|c|c|}
\hline Variable & Mean & $\begin{array}{l}\text { Standard } \\
\text { Deviation }\end{array}$ & $\begin{array}{l}\text { P for Student's } t \text {-Test or } \\
\text { ANOVA }\end{array}$ & $\begin{array}{l}\text { P for Wilcoxon Rank-Sum Test or Kruskal- } \\
\text { Wallis }\end{array}$ \\
\hline $\begin{array}{l}\text { Insurance } \\
\text { - Uninsured } \\
\text { - HICS }\end{array}$ & $\begin{array}{l}420.2 \\
22.2\end{array}$ & $\begin{array}{l}805.9 \\
147.4\end{array}$ & $<0.001$ & $<0.001$ \\
\hline $\begin{array}{l}\text { Sex } \\
\text { - Male } \\
\text { - Female }\end{array}$ & $\begin{array}{l}222.4 \\
135.9\end{array}$ & $\begin{array}{l}593.8 \\
502.7\end{array}$ & $<0.001$ & $<0.001$ \\
\hline $\begin{array}{l}\text { Illness } \\
\text { - Non-specific } \\
\text { - Z-group } \\
\text { - ACSC }\end{array}$ & $\begin{array}{l}144.4 \\
256.1 \\
93.7\end{array}$ & $\begin{array}{l}520.3 \\
620.0 \\
427.5\end{array}$ & $<0.001$ & $<0.001$ \\
\hline $\begin{array}{l}\text { Facility level } \\
\text { - Health centres } \\
\text { - District hospital } \\
\text { - Provincial hospital }\end{array}$ & $\begin{array}{l}64.4 \\
677.6 \\
69.8\end{array}$ & $\begin{array}{l}130.2 \\
1069.6 \\
251.9\end{array}$ & $<0.001$ & $<0.001$ \\
\hline $\begin{array}{l}\text { Domicile } \\
\text { - Non-proximity } \\
\text { - Proximity }\end{array}$ & $\begin{array}{l}671.0 \\
69.9\end{array}$ & $\begin{array}{l}1055.2 \\
270.1\end{array}$ & $<0.001$ & $<0.001$ \\
\hline $\begin{array}{l}\text { Time } \\
\text { - Pre-2013 } \\
\text { - Post-2013 }\end{array}$ & $\begin{array}{l}222.0 \\
106.9\end{array}$ & $\begin{array}{l}633.4 \\
383.7\end{array}$ & $<0.001$ & $<0.001$ \\
\hline $\begin{aligned} & \text { Age group in years } \\
& \text { - } 0-7 \\
& \text { - } 8-15 \\
& \text { - } 16-30 \\
&- 31-60 \\
& \text { - }>60\end{aligned}$ & $\begin{array}{l}158.5 \\
220.5 \\
220.0 \\
152.9 \\
108.8\end{array}$ & $\begin{array}{l}435.2 \\
473.5 \\
615.8 \\
537.7 \\
471.1\end{array}$ & $<0.001$ & $<0.001$ \\
\hline
\end{tabular}

Second, it was impossible to track information on the same individual across facilities. This problem stemmed from a difficulty in accessing patient's national identification numbers. In reality, national identification numbers cannot be shared by hospital staff members because this could violate individual patient confidentiality. Therefore, in the analysis, the authors addressed this problem by using an individual hospital number as a unique identifier instead.

Third was about data quality. Data quality at local health facilities were almost always more problematic than those at the central authority. For example, some records of Myanmar patients were miscoded as UCS beneficiaries. The authors solved this problem by excluding the poor quality data and fortunately, these poor quality records accounted only for a small fraction of the whole dataset.

Fourth, the analysis was not totally free from misclassification bias. An obvious instance is the change in the insurance status of an individual within a year. For example, it is possible that during the first visit an insured migrant was coded as HICS but in the later visit the same individual might be coded as uninsured if he/she failed to show his/her insurance card to the providers. Though the providers were likely to search the insurance information of that individual by his/her name, the erroneous check might still persist due to language differences.

Fifth, though this point is in fact the nature of the data rather than methodological limitation, it is still worth mentioning. That is, this study employed a treatment-control design. Despite its practicality in assessing policy issue, the treatment-control approach is always inferior to an experimental study which applies randomization and stringent control on the contextual environment to minimize selection bias and unobserved characteristics. $^{27,28}$ 
Table 9 Multivariable Analysis of OP OOP (in Baht) by the TPM

\begin{tabular}{|c|c|c|c|c|c|c|}
\hline \multirow[b]{2}{*}{ Part I } & \multirow[b]{2}{*}{ 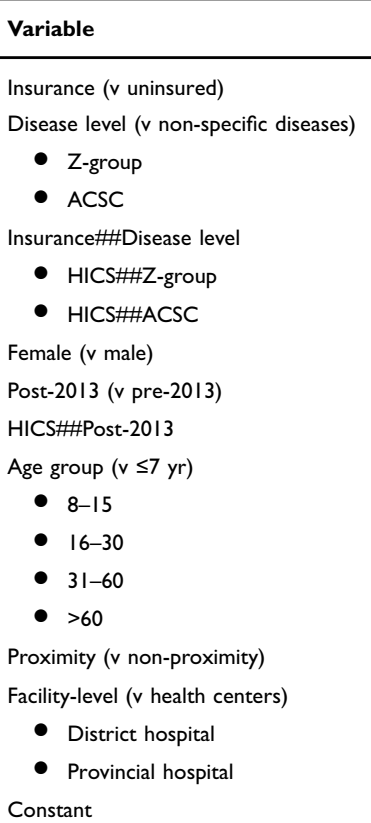 } & $\frac{\text { Coef }}{-5.037}$ & $\begin{array}{l}\text { SE } \\
0.061\end{array}$ & $\begin{array}{l}\mathbf{P} \\
<0.001\end{array}$ & \multicolumn{2}{|c|}{ 95\% Confidence Interval } \\
\hline & & $\begin{array}{l}-5.037 \\
-0.823 \\
0.652 \\
0.863 \\
-0.012 \\
-0.405 \\
-0.497 \\
1.141 \\
\\
0.921 \\
0.442 \\
0.682 \\
0.484 \\
-0.602 \\
-0.344 \\
-2.048 \\
2.681\end{array}$ & $\begin{array}{l}0.061 \\
0.036 \\
0.051 \\
\\
0.087 \\
0.115 \\
0.037 \\
0.043 \\
0.085 \\
\\
0.074 \\
0.048 \\
0.054 \\
0.099 \\
0.055 \\
\\
0.113 \\
0.121 \\
0.108\end{array}$ & $\begin{array}{l}<0.001 \\
<0.001 \\
<0.001 \\
<0.001 \\
0.916 \\
<0.001 \\
<0.001 \\
<0.001 \\
<0.001 \\
<0.001 \\
<0.001 \\
<0.001 \\
<0.001 \\
0.002 \\
<0.001 \\
<0.001\end{array}$ & $\begin{array}{l}-5.157 \\
-0.894 \\
0.552 \\
\\
0.691 \\
-0.239 \\
-0.478 \\
-0.581 \\
0.974 \\
\\
0.775 \\
0.348 \\
0.575 \\
0.289 \\
-0.710 \\
-0.566 \\
-2.286 \\
2.469\end{array}$ & $\begin{array}{l}-4.917 \\
-0.752 \\
0.753 \\
1.034 \\
0.214 \\
-0.333 \\
-0.414 \\
1.308 \\
\\
1.067 \\
0.537 \\
0.788 \\
0.679 \\
-0.493 \\
-0.122 \\
-1.811 \\
2.893\end{array}$ \\
\hline Part 2 & 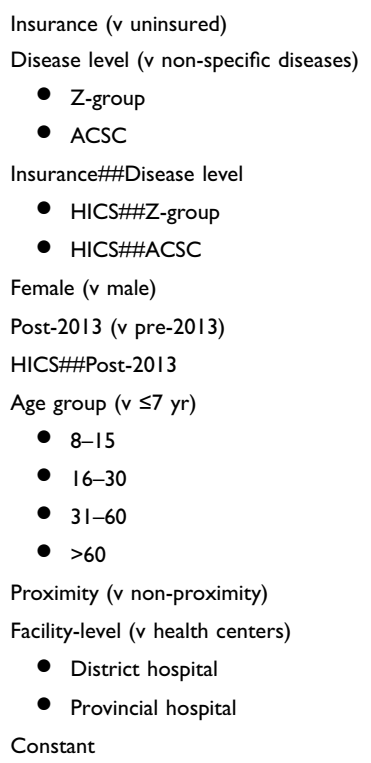 & $\begin{array}{l}-0.677 \\
0.029 \\
-0.292 \\
\\
0.423 \\
0.573 \\
-0.091 \\
-0.192 \\
0.174 \\
\\
0.179 \\
0.576 \\
0.627 \\
0.804 \\
-0.450 \\
1.667 \\
0.841 \\
4.995\end{array}$ & $\begin{array}{l}0.186 \\
0.025 \\
0.039 \\
0.116 \\
0.137 \\
0.025 \\
0.031 \\
0.130 \\
0.046 \\
0.032 \\
0.035 \\
0.090 \\
0.049 \\
0.050 \\
0.058 \\
0.050\end{array}$ & $\begin{array}{l}<0.001 \\
0.241 \\
<0.001 \\
<0.001 \\
<0.001 \\
<0.001 \\
<0.001 \\
0.180 \\
<0.001 \\
<0.001 \\
<0.001 \\
<0.001 \\
<0.001 \\
<0.001 \\
<0.001 \\
<0.001\end{array}$ & $\begin{array}{l}-1.041 \\
-0.020 \\
-0.370 \\
0.196 \\
0.304 \\
-0.140 \\
-0.253 \\
-0.080 \\
\\
0.088 \\
0.512 \\
0.558 \\
0.627 \\
-0.546 \\
1.570 \\
0.727 \\
4.897\end{array}$ & $\begin{array}{l}-0.313 \\
0.078 \\
-0.215 \\
\\
0.650 \\
0.842 \\
-0.042 \\
-0.131 \\
0.428 \\
\\
0.270 \\
0.639 \\
0.696 \\
0.981 \\
-0.354 \\
\\
1.764 \\
0.955 \\
5.094\end{array}$ \\
\hline Both parts & $\begin{array}{l}\text { Insurance ( } \mathrm{v} \text { uninsured) } \\
\text { Disease level ( } \mathrm{v} \text { non-specific diseases) } \\
\text { - Z-group } \\
\text { - } \text { ACSC } \\
\text { Female ( } \mathrm{v} \text { male) } \\
\text { Post-2013 ( } \mathrm{v} \text { pre-2013) } \\
\text { Age group ( } \mathrm{v} \leq 7 \mathrm{yr}) \\
\text { - } 8-15 \\
\text { - } 16-30 \\
\text { - } 31-60 \\
\text { - }>60 \\
\text { Proximity ( } \mathrm{v} \text { non-proximity) } \\
\text { Facility-level ( } \mathrm{v} \text { health centers) } \\
\text { - District hospital } \\
\text { - Provincial hospital }\end{array}$ & $\begin{array}{l}-293.489 \\
-18.274 \\
-22.301 \\
-30.104 \\
-37.670 \\
42.301 \\
86.353 \\
105.692 \\
132.951 \\
-95.033 \\
236.955 \\
14.938\end{array}$ & $\begin{array}{l}6.026 \\
4.168 \\
5.838 \\
4.191 \\
4.330 \\
\\
5.818 \\
3.994 \\
5.352 \\
19.697 \\
8.555 \\
\\
9.064 \\
4.110\end{array}$ & $\begin{array}{l}<0.001 \\
<0.001 \\
<0.001 \\
<0.001 \\
<0.001 \\
<0.001 \\
<0.001 \\
<0.001 \\
<0.001 \\
<0.001 \\
<0.001 \\
<0.001\end{array}$ & $\begin{array}{l}-305.300 \\
-26.444 \\
-33.743 \\
-38.317 \\
-46.156 \\
\\
30.897 \\
78.525 \\
95.202 \\
94.345 \\
-111.801 \\
\\
219.191 \\
6.883\end{array}$ & $\begin{array}{l}-281.677 \\
-10.105 \\
-10.859 \\
-21.891 \\
-29.184 \\
53.704 \\
94.181 \\
116.182 \\
171.557 \\
-78.265 \\
\\
254.720 \\
22.992\end{array}$ \\
\hline
\end{tabular}

Abbreviations: Coef, coefficient; SE, standard error. 
Further studies on other aspects of the HICS are recommended. These include qualitative studies on providers' and users' experience towards the policy and quantitative studies that scrutinize the equity angles of HICS; for instance, whether and to what extent the HICS benefit the poor in relation to the rich. Such a research question may require a more intricate dataset from the primary household survey. Besides, there is a need for further investigation on HICS from the policy angle. Certain research topics in this respect include the financial sustainability of the system and the social return on investment from the HICS operation.

\section{Conclusion}

It is clear that HICS helped reduce financial implication due to OOP at point of care among the insured migrants. The findings suggested that the HICS insurees paid fewer OOP than uninsured migrants by 2471 Baht (US\$ 75) and 293 Baht (US\$ 9) for IP and OP, respectively. Disease severity was the main determinant that contributed to increased IP OOP and OP OOP. Hospital attendance after 2013 tended to cause fewer OOP than that before 2013, the year when the HICS extended its benefit package. A deeper insight into the financing aspects of the HICS from supply-side perspectives should be examined. Further studies that delve into equity angles of the HICS, whether and to what extent the HICS financially benefit migrants in different economic status, are recommended.

\section{Abbreviations}

ACA, Affordable Care Act; ACSC, Ambulatory Care Sensitive Condition; ANOVA, analysis of Variance; ART, antiretroviral treatment; CLM, Cambodia, Lao PDR and Myanmar; DRG, diagnostic related groups; GLM, Generalized Linear Model; HICS, Health Insurance Card Scheme; ICD-10, International Classification of Diseases version 10; IP, inpatient; MOPH, Ministry of Public Health; NV, nationality verification; OOP, out-of-pocket payment; OP, outpatient; SDG, Sustainable Development Goals; TPM, Tow-path model; UCS, Universal Coverage Scheme; UHC, Universal Health Coverage; WHA, World Health Assembly.

\section{Ethics Approval and Consent to Participate}

Ethical approval was received from the Institute for the Development of Human Research Protections in Thailand
(IHRP 1778/2557). All data are kept anonymous. Dissemination of the findings can be done only for academic interest without disclosing individual information.

\section{Data Sharing Statement}

The data appearing in this article were under license for the current study only, and are not publicly available. The data are however available upon reasonable request, conditional upon the permission of the International Health Policy Program (IHPP).

\section{Acknowledgement}

The authors immensely thank local providers in the study area for their support throughout the fieldwork. Advice and suggestions from Dr Viroj Tangcharoensathien and Prof Dame Anne Mills are massively grateful.

\section{Author Contributions}

RS and SN set the study design. RS and SN led the data collection with assistance from the team members. RS, WK, MP and SN were responsible for data analysis. RS, WK and MP checked the accuracy of data interpretation. WK and MP crafted the first draft of the manuscript under the supervision of RS and SN. All authors contributed to data analysis, drafting and revising the article, gave final approval of the version to be published, and agree to be accountable for all aspects of the work.

\section{Funding}

This research was funded by the Health Systems Research Institute. IHPP provided in-kind support, such as meeting venue and documents.

\section{Disclosure}

The authors declare that they have no competing interests.

\section{References}

1. McAuliffe M, Ruhs M. World Migration Report 2018. Geneva: International Organization for Migration; 2017.

2. Koser K, Laczko F. World Migration Report 2010: The Future of Migration: Building Capacities for Change. Geneva: International Organization for Migration. 2010; 115.

3. Macpherson DW, Gushulak BD, Macdonald L. Health and foreign policy: influences of migration and population mobility. Bull World Health Organ. 2007;85(3):200-206. doi:10.2471/BLT.06.036962

4. World Health Organization. 60th assembly. Resolution WHA60. 26workers' health: global plan of action. Resolution WHA6026. Geneva: WHO. 2007:8. doi:10.1094/PDIS-91-4-0467B

5. World Health Organization. 61st assembly. Resolution WHA61.17 health of migrants. Resolution WHA61.17. Geneva: WHO. 2008. 
6. United Nations. Global compact for migration United Nations; New York, NY, USA; 2018. [cited April 2018]. Available from: https:// refugeesmigrants.un.org/migration-compact. Accessed December 4, 2019.

7. Tangcharoensathien V, Mills A, Palu T. Accelerating health equity: the key role of universal health coverage in the sustainable development goals. BMC Med. 2015;13(1):101. doi:10.1186/s12916-0150342-3

8. Guinto RLLR, Curran UZ, Suphanchaimat R, Pocock NS. Universal health coverage in 'One ASEAN': are migrants included? Glob Health Action. 2015;8(1):25749. doi:10.3402/gha.v8.25749

9. Office of Foreign Workers Administration. Statistics of remaining cross-border migrants holding work permit in Thailand as of October 2018 [Internet]; 2018 [cited June 13, 2019]. Available from: www.doe.go.th/prd/assets/upload/files/alien_th/ 98802fed607243cb1c1afe248b3d29eb.pdf. Accessed December 4, 2019.

10. Suphanchaimat R, Putthasri W, Prakongsai P, Tangcharoensathien V. Evolution and complexity of government policies to protect the health of undocumented/illegal migrants in Thailand - the unsolved challenges. Risk Manag Healthc Policy. 2017;10:49-62. doi:10.2147/ RMHP.S130442

11. National Council for Peace and Order. Temporary measures to problems of migrant workers and human trafficking (Order No.118/ 2557). Bangkok: NCPO;2014. 118/2557.

12. Health Insurance Group. Health Card for Uninsured Foreigners and Health Card for Mother and Child. Seminar on Measures and Protocols of Medical Examination, Insuring Migrants and Protecting Maternal and child health. Best Western Grand Howard Hotel, Bangkok: Office of the Permanent Secretary, Ministry of Public Health; 2013.

13. Suphanchaimat R. "Health Insurance Card Scheme" for CrossBorder Migrants in Thailand: Responses in Policy Implementation \& Outcome Evaluation. London: Faculty of Public Health and Policy, London School of Hygiene and Tropical Medicine, University of London; 2017.

14. Mihaylova B, Briggs A, O’Hagan A, Thompson SG. Review of statistical methods for analysing healthcare resources and costs. Health Econ. 2011;20(8):897-916. doi:10.1002/hec.1653

15. Mathauer I, Wittenbecher F. Hospital payment systems based on diagnosis-related groups: experiences in low- and middle-income countries. Bull World Health Organ. 2013;91(10):746a-756a. doi:10.2471/BLT.12.115931

16. Pannarunothai S. DRG in Thailand: Development Up to the Thai Casemix Version 5. Bangkok: Joint Learning Network in Universal Health Coverage; 2010.

17. Tangcharoensathien VPW, Vasavid C, Prakongsai P, et al. Thailand Health Financing Review 2010. Bangkok: Thai Working Group on Observatory of Health Systems and Policy; 2010.
18. Longman JM, Passey ME, Ewald DP, Rix E, Morgan GG. Admissions for chronic ambulatory care sensitive conditions - a useful measure of potentially preventable admission? BMC Health Serv Res. 2015;15(1):472. doi:10.1186/s12913-015-1137-0

19. Vuik SI, Fontana G, Mayer E, Darzi A. Do hospitalisations for ambulatory care sensitive conditions reflect low access to primary care? An observational cohort study of primary care usage prior to hospitalisation. BMJ Open. 2017;7(8):e015704. doi:10.1136/bmjopen-2016-015704

20. Onarheim KH, Melberg A, Meier BM, Miljeteig I. Towards universal health coverage: including undocumented migrants. BMJ Glob Health. 2018;3(5):e001031. doi:10.1136/bmjgh-2018-001031

21. Chen W, Zhang Q, Renzaho AMN, Zhou F, Zhang H, Ling L. Social health insurance coverage and financial protection among rural-tourban internal migrants in China: evidence from a nationally representative cross-sectional study. BMJ Glob Health. 2017;2(4): e000477. doi:10.1136/bmjgh-2017-000477

22. Zhang A, Nikoloski Z, Mossialos E. Does health insurance reduce out-of-pocket expenditure? Heterogeneity among China's middleaged and elderly. Soc Sci Med. 2017;190:11-19. doi:10.1016/j. socscimed.2017.08.005

23. Kominski GF, Nonzee NJ, Sorensen A. The affordable care act's impacts on access to insurance and health care for low-income populations. Annu Rev Public Health. 2017;38:489-505. doi:10.1146/annurevpublhealth-031816-044555

24. Srithamrongsawat S, Wisessang R, Ratjaroenkhajorn S. Financing Healthcare for Migrants: A Case Study from Thailand. Nonthaburi, Thailand: Health Insurance System Research Office/Health Systems Research Institute; 2009.

25. Pudpong N, Durier N, Julchoo S, Sainam P, Kuttiparambil B, Suphanchaimat R. Assessment of a voluntary non-profit health insurance scheme for migrants along the Thai-Myanmar border: a case study of the migrant fund in Thailand. Int $J$ Environ Res Public Health. 2019;16(14):2581. doi:10.3390/ijerph16142581

26. Hasuwannakit S. Including Stateless People in Universal Health Coverage: Policy Recommendation for Thailand. Antwerp: Orientation Health Systems Management and Policy, Institute of Tropical Medicine Antwerp; 2012.

27. Craig P, Cooper C, Gunnell D, et al. Using natural experiments to evaluate population health interventions: new MRC guidance. $J$ Epidemiol Community Health. 2012;66(12):1182-1186. doi:10.1136/ jech-2011-200375

28. Meyer BD. Natural and quasi-experiments in economics. J Bus Econ Stat. 1995;13(2):151-161.

29. National Statistical Office. Population and housing census [Internet]. 2014 [cited December 12, 2019]. Available from: http://www.nso.go. th/sites/2014/Documents/pop/2553/Results_report2553.pdf. Accessed December 12, 2019.
Risk Management and Healthcare Policy

\section{Publish your work in this journal}

Risk Management and Healthcare Policy is an international, peerreviewed, open access journal focusing on all aspects of public health, policy, and preventative measures to promote good health and improve morbidity and mortality in the population. The journal welcomes submitted papers covering original research, basic science, clinical \& epidemiological studies, reviews and evaluations, guidelines, expert opinion and commentary, case reports and extended reports. The manuscript management system is completely online and includes a very quick and fair peer-review system, which is all easy to use. Visit http://www.dovepress.com/testimonials.php to read real quotes from published authors. 